\title{
Burnout in Social Justice and Human Rights Activists: Symptoms, Causes and Implications
}

\author{
CHER WEIXIA CHEN AND PAUL C. GORSKI*
}

\begin{abstract}
Although people involved in every kind of professional or volunteer work can be susceptible to vocational burnout, research suggests that social justice and human rights (SJHR) activists, whose activist work is fraught with unique challenges, can be especially susceptible to it. Building on a small but growing body of scholarship on SJHR activist burnout, this study is an attempt to gain insight into SJHR activists' own experiences. In order to deepen the relatively slim present understandings of SJHR activist burnout, we adopted a grounded theory approach to analyse interview data from $22 \mathrm{SJHR}$ activists involved in a wide variety of SJHR movements and organizations in the United States. This analysis revealed patterns in the activists' perceptions of the symptoms, causes, and implications of their burnout and pointed to several dimensions of the internal cultures of United States SJHR movements and organizations, including, in the words of one our participants, a 'culture of martyrdom', that hasten activist burnout and, as a result, render SJHR activism less effective and efficient. We discussed these findings and how they might inform efforts to strengthen SJHR movements by tending to the well-being of SJHR activists.
\end{abstract}

Keywords: burnout; culture of martyrdom; social justice and human rights activism

\section{Introduction}

Social justice and human rights (SJHR) activists, whose work renders them susceptible to emotional and physical exhaustion (Maslach and Gomes 2006), need tools to tend to their own well-being. Unfortunately, most people in our own circles of SJHR activists in the United States are not intentional about tending to their own well-being. Doing so is associated in some SJHR circles with a lack of commitment or with self-indulgence (Plyler 2006). Some rights defenders and activists perceive self-care as contradicting an implicit pact of 'selflessness' as Rodgers (2010) found in her study of people working with Amnesty International. The combination of the emotional toll of SJHR work and the culture of selflessness can hasten 'activist burnout', a condition, described in more detail later, which often results in people scaling back on or fully disengaging from their SJHR activism (Rettig 2006).

* Cher Weixia Chen (wchen12@gmu.edu) is an Assistant Professor in New Century College and a Research Fellow in the Center for the Advancement of Well-Being, George Mason University, Virginia, USA. Her scholarship centres on human rights. Paul C. Gorski (pgorski1@gmu.edu) is an Associate Professor in New Century College and a Research Fellow in the Center for the Advancement of Well-Being, George Mason University. His work and passion is social justice activism. 
This study was conceived out of a desire to learn more about the implications of these and other conditions for the physical and emotional well-being of SJHR activists. Much has been written about activist burnout and the toll SJHR activism can take emotionally and physically on activists (e.g. Maslach and Gomes 2006; Klandermans 2003). Most of this scholarship has focused on people's experiences with burnout in particular SJHR organizations or movements in the United States, such as the Plowshares (Nepstad 2004) or the peace movement (Gomes 1992). Although some researchers have speculated on the range of symptoms of burnout among activists, few have attempted to document those symptoms through the stories of the activists themselves. Given the deleterious effects activist burnout can have on social movementson the work of rights defenders and other activists-it was the aim of this study to build upon the existing scholarship by helping to map out more precisely what activist burnout looks and feels like for people in a wide array of SJHR contexts in the United States. Doing so could be one step toward being able to identify research-based strategies for mitigating activist burnout and tending to the well-being of SJHR activists.

In order to do so, using a grounded theory approach, we analysed data from interviews with 22 United States-based SJHR activists who self-identified as having experienced activist burnout. Our primary research question was: How do United States-based social justice and human rights activists characterize the symptoms, causes, and implications of activist burnout? This research question was framed purposefully and specifically to capture nuances related to how SJHR activists understand and describe their own experiences with activist burnout rather than attempting to more broadly theorize the breadth of burnout among all SJHR activists. As conceptualized for this study, symptoms referred to the micro-effects that burnout had on the activists-how they experienced burnout physically, emotionally, and otherwise. Causes referred to participants' perceptions of the conditions and experiences that led to their burnout. Finally, implications referred to the impact of the activists' burnout on their activism and their lives more generally.

\section{Literature review}

A growing body of scholarship describes the challenges associated with being an SJHR activist. For example, in her study of the stressors and rewards US peace activists associate with their activism, Gomes (1992) found public apathy, the slowness of progress, a lack of resources, and tense relationships within the peace movement to be among their most common stressors. Others, such as Downton and Wehr (1998), who also studied the experiences of peace activists, and Nepstad (2004), who examined activist commitment in the Plowshares movement, focused on how activists sustained themselves through these sorts of stressors. Downton and Wehr (1998) found, for example, that activists who persisted in the peace movement despite the stressors were likely to have created close bonds with movement leaders, learned 
how to manage criticism, and associated success in their activism with their personal growth. The ability to withstand these stressors is described by these and other scholars as activist persistence or activist sustainability.

\section{Activist burnout}

The inverse of the activist persistence or activist sustainability as examined by these scholars is activist burnout. The notion of burnout was conceptualized initially by Freudenberger (1974). Unlike the common use of 'burnout', which might describe temporary bouts with work stress, Freudenberger described something more debilitating and long-term. Building on his conception, Maslach and Leiter (2005) clarified that burnout is not just about having a bad day or a temporary struggle with stress. It is a chronic condition. Burnout results in people once highly committed to a movement or cause or organization growing mentally exhausted (Schaufeli and Buunk 2002) and, as a result, losing the idealism and spirit that once drove them to work for social change (Pines 1994).

Social justice and human rights activists are especially susceptible to burnout because they put pressure on themselves to have a significant impact on the world around them (Pines 1994). SJHR activism requires an emotional investment, or what Goodwin and Pfaff (2001) described as emotional labour. The investment of emotional labour among SJHR activists may be heightened even in comparison with that expended by people doing other forms of activism for two reasons. First, according to Maslach and Gomes (2006: 43), activism related to social justice and human rights concerns requires activists to develop a deep understanding of overwhelming social conditions related to suffering and oppression-conditions that society as a whole often is 'unable or unwilling to face'. This burden weighing on SJHR activists' consciousness increases their levels of stress and self-inflicted pressure, elevating the threat of activist burnout (Kovan and Dirkx 2003). Secondly, despite the emotional and physical toll SJHR activism takes on SJHR activists, studies have shown that many SJHR organizations and activist groups dismiss the importance of discussing or reflecting upon activist burnout (Pigni 2013; Plyler 2006). This lack of acknowledgement-in some cases, a culture of suppressing concerns about activists' well-being altogether (Rodgers 2010)—can hasten burnout among SJHR activists (Nair 2004). Rodgers (2010) referred to this suppression of concern or conversation about burnout as a culture of selflessness in which activists in effect police each other's commitment to causes by belittling attempts at self-care.

Other stressors have been associated with activist burnout within the SJHR community. One such stressor, as documented by Gomes (1992) in the United States peace movement and Hopgood (2006) in the International Secretariat of Amnesty International, arises from tense and unpeaceful relationships among people within activist organizations. Reflecting one of the possible implications of the development of organizations full of people with strong 
emotional investments in their work, Hopgood (2006) found particularly deep tensions between workers who wanted the organization to remain focused on the issues it traditionally had addressed and on being a sort of voice for the voiceless and their colleagues who wanted the organization to take stronger and more overtly political stances and to broaden its reach to address additional human rights issues. He found that, despite a history of attempts by the organization's leadership, they had been unable to alleviate these tensions. Other commonly cited stressors include workload and time pressures (Klandermans 2003; Vaccaro and Mena 2011). When these and other challenges accumulate, the result can be debilitating. Maslach and Gomes (2006: 43) described it this way: 'the initial "fire" of enthusiasm, dedication, and commitment to the cause has "burned out", leaving behind the smoldering embers of exhaustion, cynicism, and ineffectiveness'.

The symptoms of burnout are multi-dimensional. In their summary of 25 years of burnout scholarship, Schaufeli and Buunk (2002) organized burnout symptoms into five categories:

(1) affective manifestations, characterized by changes in mood, often related to depression and anxiety;

(2) cognitive manifestations, characterized by lags in attention, memory, and concentration;

(3) physical manifestations, characterized by health challenges such as headaches, high blood pressure, and illnesses;

(4) behavioural manifestations, characterized by behavioural changes that impact productivity and health, ranging from increased procrastination to substance abuse; and

(5) motivational manifestations, characterized by diminishing drive and increased feelings of alienation and despondency.

With regard to burnout within the SJHR community, for example, Kovan and Dirkx (2003) observed cognitive manifestations among environmental activists and Vaccaro and Mena (2011) found physical manifestations in lesbian, gay, bisexual, transgender, and queer-identifying (LGBTQ) activist youth of colour.

A related and perhaps even more serious issue concerning activist burnout is its impact on movements to secure human rights and social justice (Plyler 2006). Activist burnout, together with contributing factors such as unsupportive work environments in SJHR activist organizations, has been identified by some scholars as the leading factors contributing to activists' burnout and resulting disengagement from their activism (Cox 2009, 2011; Downton and Wehr 1998; Klandermans 2003; Pines 1994). In particular, those who neglect the signals of burnout tend to end up leaving their activism at least temporarily (Gomes and Maslach 1991), which could disrupt SJHR movements. 
Klandermans (2003), for example, in a study about burnout among peace activists, found that activists who ended their involvement with the peace movement because of burnout tended to quit political activism altogether. The burnout hurt them individually, but also hurt the sustainability of the movement. This is why Rettig (2006: 16) defined burnout as 'the act of involuntarily leaving activism, or reducing one's level of activism'. She explained:

When an activist burns out, she typically derails her career and damages her self-esteem and relationships. She also deprives her organization and movement of her valuable experience and wisdom. The worst problem, however, may be that when an activist burns out she deprives younger activists of a mentor, thus making them more likely to burn out. (Rettig 2006: 16)

Some scholars (e.g. Kovan and Dirkx 2003; Pines 1994) have argued that what distinguishes SJHR activist burnout from other types of activist burnout is that, by having a deleterious effect on activists and movements, it helps to allow injustice and rights abuses to persist. This, in turn, becomes another layer of pressure on SJHR activists.

\section{Responding to activist burnout}

Several scholars have recommended ways to respond to activist burnout, although usually these recommendations are based, not on evidence for what has worked, but on studies on the impact of burnout. Wollman and Wexler (1992) suggested that the tools of psychology could help activists and recommended both didactic and experiential approaches to addressing their burnout. Downton and Wehr (1998), based on their study of 30 peace activists, identified several characteristics of activists who have avoided burnout. Maslach and Gomes (2006) recommended that in order to cope with burnout activists work on improving their health, find ways to relax in strenuous situations, and recognize their own limits.

Other suggestions have included encouraging activists to acknowledge that their own needs are important (Kovan and Dirkx 2003), learning how to get out of a negative 'blaming mode' (Nair 2004: 31), and finding balance between self-care and activist work (Maslach and Leiter 2005). Notably, with the exception of Wollman and Wexler (1992), these scholars described shifts in dispositions or approaches to activism, while not describing what sorts of actions individual activists could take to tend more effectively to their own well-being.

Effectively addressing the issue of activist burnout requires not only individual effort, but also support from activist communities and organizations (Maslach and Leiter 2005). For example, Nepstad (2004) found that communitybuilding strategies and consistent material and emotional support helped participants in the Plowshares movement overcome burnout. Maslach and Gomes 
(2006) recommended that activist organizations should acknowledge movement accomplishments and attend more thoughtfully to within-movement interpersonal relationships. Others have suggested that activist burnout might be mitigated through organizational efforts to provide opportunities for professional growth (Kovan and Dirkx 2003), to cultivate more peaceful and equitable relationships among activists (Gomes 1992), and to assist activists in coping with stress through exercise and hobbies (Maslach and Leiter 2005).

To date, with few exceptions (e.g. Plyler 2006; Rodgers 2010) a majority of studies on activist burnout in SJHR contexts have focused on determining whether and to what extent it exists in various contexts. Much of the deeper analysis of activist burnout as experienced by individual activists has been, in essence, a by-product of studies about activist sustainability and persistence (e.g. Maslach and Leiter 2005; Nepstad 2004). As a result, the individual and institutional recommendations for mitigating burnout generally are not based on focused analyses of activists' stories about the symptoms, causes, and implications of their burnout, but are rather more speculative in nature. It is the purpose of this study to begin to fill that gap in the existing understandings of activist burnout, and particularly of SJHR activist burnout.

\section{Method}

We analysed data from interviews with 22 SJHR activists on their experiences with and observations of activist burnout.

\section{Participants}

Potential participants were identified through formal and informal networks of activists using a process often referred to as snowball sampling (Creswell 2009). Several activists known by the researchers were asked for ideas of potential interviewees who, in turn, recommended other potential interviewees. Requests for participation also were posted on relevant Facebook pages and emailed to numerous email groups used by SJHR activists. All participants met three criteria:

(1) they identified their primary life's work-not just their formal jobs, but their life's work —as revolving around social justice or human rights activism;

(2) they experienced activist burnout as conceptualized by Rettig (2006), who defined it as having to disengage from one's activism at least temporarily due to combinations of emotional and physical exhaustion connected with that activism (as opposed to more generalized feelings of exhaustion or life challenges), and then after finding strategies for self-care, returned to their activism; and

(3) they considered their self-care strategies to be important to their activist lives. 
In other words, participants were sought who currently were engaged in SJHR activism, but who also had experienced and recovered from activist burnout, as we believed they would have unique insights into the symptoms, causes, and consequences of their burnout.

In the search for participants activism was broadly defined. Couch's (2004: 15) definition captured the breadth of the types of activist sought for the study:

An activist may ... be a member of a social movement, popular struggle, trade union, collective, network, NGO, or civic or religious organisation, a scholar or student, or an individual unaffiliated with any group.

SJHR activism was conceived broadly, as well, as activism to resist or overturn policies and practices that repress rights or that oppressively exploit humans, non-human animals, or the environment.

The focus of the participants' activism covered a wide range of SJHR issues, including children's rights, immigrant rights, animal rights, environmental justice, racial justice, education justice, women's rights, cultural sustainability in black communities, anti-war and peace, anti-trafficking, and restorative justice, among others. Some, but not all, participants worked in jobs related to their activism. Only four participants worked in SJHR-related NGOs or non-profit organizations. However, simply being employed by such an agency would not have qualified somebody to participate if they were not involved in SJHR activism outside of their paid jobs. So, unlike most previous studies of activist burnout, the majority of participants in this study did not conceive their 'activism' in terms of working with a specific NGO or with having a paid job related to their activism. In other words, they were not 'employees' of their movements, but rather activists who became involved in movements and movement organizations as volunteers, outside the context of, or in addition to, their paid jobs. This design was made to maximize the extent to which activism-related tensions could be disassociated from the sorts of workplace tensions that could occur in any workplace, such as issues related to remuneration.

The interviewees were diverse in terms of age (ranging from 25 to 61 years old) and activist experience (ranging from seven to 44 years). In terms of race, 13 identified themselves as white and nine identified as people of colour. Among the participants of colour, six identified as multiracial, one as African American, one as South Asian, and one as Asian American. Socio-economically, two identified as people in poverty, five as working class, nine as middle class, five as managerial class, and none as wealthy. Two participants declined to identify their socio-economic status. A majority of the participants-19 of 22-identified as women and three identified as men. Perhaps the most formidable methodological challenge faced by the researchers was finding men who were willing to participate in this study. We speculate as to what this might mean in the discussion section of this essay. 


\section{Interviews}

The researchers conducted roughly 60-minute interviews by telephone or Skype (a Web-based videophone program) with each participant. Items for the interview protocol were drawn from relevant themes identified by existing scholarship on activist burnout. The interviews followed a semi-structured approach of the general interview guide model described by Patton (1990), in which we started with a standard set of questions (see Appendix 1), but proceeded through them with ample flexibility to be able to follow leads that emerged from the activists' stories. After several stages of drafting and redrafting the interview protocol a pilot test was conducted with four SJHR activists who fit the participant criteria. The final protocol contained twelve questions, each with one or two follow-up prompts. Following two broad questions inquiring about participants' activist backgrounds, these questions were grouped around three broad and overlapping themes: (1) participants' experiences with activist burnout; (2) participants' engagement of well-being practices in response to burnout and insights about their burnout recovery; and (3) participants' perceptions of the relationship between their burnout and well-being practices. This study draws primarily on data attained from questions in the first two sections of the protocol.

Interviews were transcribed. They were then checked again against the audio recordings. Participants were given the option to review their transcripts in order to correct any errors or clarify points they made during the interviews.

\section{Analysis}

Interview data were analysed using the three phases of Strauss and Corbin's (1990) coding process for grounded theory. First the data were organized into broad themes. It was from this process that the three major themes of symptoms, causes, and consequences of activist burnout emerged. The data organized into these themes were then re-examined in order to identify possible patterns and relationships among responses, a process which resulted in subthemes under each of these major themes. For example, this was the stage of the data analysis process through which the researchers were able to uncover the sorts of symptoms commonly identified across participants. Finally, the data organized into themes and subthemes were re-examined in order to draw out deeper intricacies related to the activists' stories. They were re-examined, for instance, in order to identify possible patterns across demographics such as race and socio-economic status.

Participants were designated pseudonyms to protect their identities.

\section{Results}

The interviews yielded several hundreds of pages of transcribed text that encompassed a wide range of issues related to activism, activist burnout, and self-care (or the lack of it) among activists. As the data were analysed, we 
suspected that we would find demographic differences in how participants experienced the symptoms, causes, and implications of their burnout. We imagined, for example, that low-income participants might have reported causes of burnout that differed from those of their wealthier counterparts, or that distinctions might be evident in the implications of burnout when we looked across the issues around which participants were basing their activism. Perhaps counter-intuitively, only one such distinction emerged: several participants of colour mentioned how racism within SJHR movements and organizations hastened their burnout-an issue discussed in more detail below. Notably, participants were not asked specifically about their perceptions of these differences-any line of questioning that would appear as fishing for particular kinds of responses was avoided. Aside from the issue of racism that participants reported within their movements, the lack of attention to demographic comparisons reflects, not a lack of curiosity about possible distinctions, but a lack of evidence in the data that such distinctions existed in the data collected and analysed.

Among 22 participants, all had experienced some level of burnout, left their activism, and eventually adopted strategies to address their burnout, allowing them finally to be able to re-engage in their activism. Many participants also referred to burnout in the larger SJHR communities and organizations with which they identified. Jill shared, for example: 'when I started in the mid- to late '90s, it was so rampant... Almost everyone I knew was dealing with some element of [burnout] and it was affecting their physical health or their emotional health or their work was really suffering.'

\section{Symptoms of SJHR activist burnout}

Jill's reflections cited above captured the three categories of general (as opposed to specifically activist) burnout symptoms identified by Schaufeli, Leiter, Maslach, and Jackson (1996): (1) exhaustion; (2) cynicism; and (3) inefficacy (or ineffectiveness) in one's work. In fact, many of the participants' experiences with activist burnout were well captured by these three symptom categories. All 22 of the activists experienced symptoms related to at least one of these categories.

However, a closer analysis revealed that these categories failed to sufficiently capture the scope and depth of the ways in which the participants seemed to understand their experiences with SJHR activist burnout. For example, rather than just feeling exhausted, many of the participants associated serious emotional or physical health ailments with the stress, long hours, and other conditions characterizing their activist work. More than cynicism, many of the activists experienced increasing levels of hopelessness and disbelief. Analysis revealed three somewhat different symptom categories as described by the participants that included those identified by Schaufeli et al. (1996) but better captured this full range of symptoms: (1) the deterioration of 
physical health; (2) the deterioration of psychological and emotional health; and (3) hopelessness.

\section{The deterioration of physical health}

Following the definition of activist burnout as a chronic condition rather than the occasional headache or bouts of exhaustion, the physical manifestations of burnout described here are those that were described by participants as debilitating and ongoing rather than mild and temporary. It is important to note, as well, that although we do not have medical evidence to independently attach these symptoms to participants' activist burnout, what we describe here, in response to this study's research question, is how the participants characterized the physical health symptoms they associated with their burnout. Under these qualifications, 17 of 22 participants ( 77.3 per cent) reported experiencing a deterioration of their physical health that they attributed to their participation in SJHR activism. The physical symptoms that participants associated with their activist burnout varied widely, including trouble eating, pneumonia, migraine headaches, and cancer, but in each case they were connected to, in Bethany's words, 'sheer exhaustion'. And in each case the symptoms were severe enough, as the participants described them, to threaten their abilities to sustain their activist work.

The most common physical health symptom described by the participants was chronic insomnia. Heidi explained: 'One of the first indicators for me is insomnia.... I'm waking up in the middle of the night thinking about how I need to do this or bring this in or what time I am meeting with these parents, and that starts repeating itself.' The insomnia became more serious for Cathy: 'I would not be able to sleep unless I took sleeping pills.'

Several participants attributed serious illnesses to the physical exhaustion created by their activism. Ellen, for example, believed she had 'ended up with pneumonia twice, in the hospital once', as a result of exhausting herself through her activism. Stella shared: 'I was physically getting sick and gaining weight-I had to have surgery.' Two participants attributed their cancer to the stress and anxiety of their activism and to the lack of spaces in their activist networks to discuss or practise self-care.

\section{The deterioration of psychological and emotional health}

Of the 22 SJHR activists interviewed, 16 (72.7 per cent) believed they had suffered serious emotional or psychological health problems as a result of their activism and the conditions surrounding that activism. Many alluded to what Rodgers (2010) called a culture of selflessness that discouraged them from tending to their own well-being as among the major roots of their burnout. They described, not just brief periods of weariness, but chronic, debilitating stress, anxiety, and depression that drove them away from their activism at least temporarily. Christopher, for example, felt 'frayed all over'. Evelyn described feeling 'emotionally devastated'. 
Depression and anxiety were common challenges. Christopher shared that, due to depression, he often struggled to get out of bed to return to his activist work. Bethany's depression began to affect her family life: 'I was really, really, really depressed. And I said I have to do something about this because I didn't even have energy to play with my children.' Stella described the moment that the stress of her SJHR activism accumulated to the point that she began having anxiety attacks: 'I was driving one day and my chest hurt so bad ... It was like I had this vice around me and it was pressing on me. I knew that it was anxiety.'

\section{Hopelessness}

Fifteen (68 per cent) of the activists, when describing their burnout, referred to feelings of hopelessness they had developed related to their activism. These activists felt overwhelmed by what they described as the challenging politics within their activist communities and the lack of progress they perceived their activism to be making. Again, following the definition of activist burnout as a chronic condition, it is important to distinguish here between descriptions of temporary frustration-the kind experienced by most activists at least occasionally-and the ongoing, debilitating hopelessness that could paralyse an activist and threaten to make one leave activism.

Several participants, for example, described feelings of despair as they questioned whether what they were doing had any effect on the injustice and abuses they were attempting to eliminate. 'You can start to think that what you're doing makes no difference', Tori shared, and 'you kind of move into despair'. Bethany added: 'You feel like, "I'm putting in all this energy and I don't see anything changing", so it gives you a sense of burnout. [You wonder], is it really working? Does it really matter that I do all this?' As they became increasingly overwhelmed, many of the activists developed increasingly cynical views about SJHR activism. When describing the challenges in her own activist life, Stella explained: 'I was just losing my soul . . . Like my soul is being injured regularly. And I was losing my spirit.' This led to feelings of failure and insufficiency, as captured by Christopher, who had the sense of 'well, I'm really tired and I don't know that I'm actually seeing measurable outcomes, things that actually tell me that I'm making a difference'.

\section{Causes of SJHR activist burnout}

The participants emphasized several aspects of SJHR activism that contributed to their activist burnout. Some overlapped with the symptoms of their burnout. For example, several activists referred to exhaustion and hopelessness as they reflected on the causes of their burnout or the burnout of other activists with whom they worked, as captured by Kara:

The issue is so huge and it's designed to turn people against one another, and just when you think you've made one step forward, or two steps 
forward, you find yourself slipping one step back. A relationship falls apart. You know, great ideas are put on the table and you can't find any funding to make it happen. Those are the kinds of things I see.

Several of the activists attributed the causes of their burnout to feeling overworked and underappreciated. 'The burnout that I feel', Patrice shared, 'is just the amount of work that there is to be done. It feels endless. It feels like a lot of heavy lifting.' Despite the overwhelming work they had to do, these activists felt that their work had gone unnoticed, which often hastened their burnout, as explained by Lisa: 'I think when you don't get credit for something ... or you don't feel valued, you don't feel important, that [contributes] greatly to burnout.'

In addition to these more general feelings of being overworked and underappreciated, the activists identified several more specific causes of their burnout. The most common of these were (1) infighting and tense relationships within activist organizations and movements; (2) deep sensitivities to injustice that made the slow process of social change difficult to bear; and (3) a lack of attention to burnout and self-care in their activist communities.

\section{Infighting and tense relationships within activist communities}

Eight of the participants cited disharmonious or hostile environments in their SJHR activist organizations or movements as a primary cause of their activist burnout. They felt that the politics within their activist communities were often cruel and deleterious to themselves and other activists. SJHR activists fighting against exploitation and disenfranchisement found some of these very conditions within their organizations and movements. Shari explained:

As with many social justice movements, there's a lot of infighting in the [anti-human trafficking] movement. And I got caught up in that. The infighting is based on 'Well, who's getting the credit for the work? Who's getting the grants for the work?'

Several participants shared how they had been 'bullied', 'attacked', and 'undermined' by fellow activists. Stella shared, for example, that 'because of the things I stand for and I care about, I was getting attacked and undermined, mostly by my colleagues.'

In the single example that emerged from the data analysis about how participants' experiences differed across identity, several of the participants of colour noted the ways they experienced racism within SJHR movements, and even within racial justice movements, and how this contributed to their activist burnout. Patrice, for example, lamented 'the wear and tear of what it is to walk around this world in our skin, just the constant [racial] microaggressions that are there and the paper cuts that occur' within social justice movements. Ellen, whose SJHR activism focuses on racial equity in schools, described how the difficulty of dealing with the everyday challenges of 
activism on top of being herself a target of racial inequity made her especially susceptible to burnout. Notably, although all participants were asked both about their own burnout and the bigger problem of burnout in their movements and organizations, not a single white participant mentioned this trouble with racism within SJHR movements that was commonly cited by participants of colour.

\section{Deep sensitivities to injustice}

One factor that distinguishes SJHR activist burnout from other forms of vocational burnout is the stress and self-inflicted pressure that comes with a deep awareness of injustice and exploitation (Kovan and Dirkx 2003). Eleven of the participants noted how their sensitivities to injustice, and the related stress and pressure, contributed to their burnout, especially as the injustices they were battling appeared too 'unwieldy'. Several, like Ellen, described becoming stuck in anger: 'it might be anger at the system or it might be anger at individuals who I feel are part of the problem or impeding progress, kind of this background anger.'

Others attributed their burnout to how their heightened sensitivities toward and awareness of injustice triggered in them a sense of urgency, creating for them another level of responsibility. Gwen shared her perceptions of this phenomenon: 'Whether we experience it ourselves or we have deeper levels of sensitivity around what's happening in the world, that leads us to then have more anxiety and depression all the time ... than other folks.'

Candace, echoing the perspectives of many of her fellow participants, described her burnout as being 'born out of a sense of urgency about the issues and passion about the issues.' Other participants described how, due to their awareness of oppression, they expected themselves to be 'super-human', to work unsustainable hours with hopes of creating instantaneous social change. In essence, these activists' proclivities for seeing and wanting to respond to injustice, which drove many of them into activism in the first place, when not managed through self-care, grew into the depression, anxiety, and other symptoms of their burnout.

\section{Lack of attention to burnout and self-care in activist communities}

As mentioned earlier, all of the activists interviewed for this study experienced some level of activist burnout that required them to leave their activism at least temporarily. Other than one participant, none found in their activist organizations or movements mentoring on coping with burnout or opportunities to have open, honest conversations about burnout. Many of the activists attributed their burnout to the absence of these opportunities. As Jill explained: 'people were afraid to even talk about [burnout] with each other. It just wasn't a topic of conversation. That made it that much worse.'

Because their activism became the central focus of their lives, several participants mentioned that, when it came to their own well-being, their response, in 
Candace's words, was 'either not noticing or noticing and ignoring the signals' of burnout. Tori observed how this phenomenon affected the larger community of activists with whom she worked: 'My experience in social justice and human rights movements has been that people want to be very monofocal, and they want to focus and work as hard as they can on the problem that they have identified... And there's sometimes a tendency to say that time not spent on that is wasted.'

Supporting existing scholarship (Plyler 2006; Rodgers 2010), many of the activists explicitly identified what Rodgers (2010) called the culture of selflessness in their organizations and movements. They described this culture as a 'culture of martyrdom' or 'guilt culture' based on an 'ethic of suffering' and complete 'self-sacrifice'. This culture was modelled for them and they were expected to comply. Referring to the source of her activist burnout, Patrice shared: 'There is also a culture of martyrdom. A lot of activist spaces where people are just killing themselves and don't engage in self-care in very comprehensive ways and don't really think about how to act in measured ways.' She, like many of the other activists we interviewed, felt they had been conditioned to believe that any consideration for self-care was self-indulgent and evidence of a lack of commitment. Heidi, an animal rights activist, shared:

When I think about it and I know that there are 13 trillion animals suffering right now in the system, a feeling of guilt might arise as I'm ... not spending every waking moment doing what I can for them ... I certainly think there's a sense of guilt. Anything that is not ... being an activist is considered a luxury or privilege or something that does not benefit animals or children or women or whatever ... the social justice issue is.

Dee similarly shared: 'In a lot of these social justice movements you hear people saying that the people we're fighting for... don't have the luxury of this so why should we?'

When asked directly whether they had experienced any mentoring in their activist communities on coping with burnout, one participant recalled a graduate class in which students talked briefly about self-care and one mentioned a single mentor who spoke with her about self-care. Confirming what some participants described as a sort of conspiracy of silence about burnout in SJHR circles, 20 of the participants could not recall a single conversation about burnout within those organizations or movements. Several described what Christopher called 'anti-mentoring' when it came to self-care and coping with burnout. Christopher explained: 'One friend and colleague of mine ... is really committed to the work, so being tired and worn out and just having your family life collapse around you is just the price of being in the game. That, to me, is anti-mentoring. I am having struggles and your response to me is essentially, "Man up and deal with it." ' Capturing the experiences of many of the other interviewees, Stella concurred: 'There's nothing in my training 
that has even come near [mentoring on burnout and self-care]. As I'm thinking about it, it sort of perpetuated the disconnect from my body-you know, you don't need to face tension, you need to rise above the tension.' Jill summarized: 'that kind of training and mentorship ... did not exist in the social justice world that I have been a part of'.

\section{Implications of SJHR activist burnout}

Sixteen (73 per cent) participants described how activist burnout, or looming burnout, had negative effects on their activist work. Patrice shared that her burnout was manifested in a 'lack of patience with conversations, my lack of patience with just having to process everything.... I reach my limit and then, okay, now I need to go hang out with the birds because they don't talk.' For Stella, the impact was even more deleterious:

I was losing my capacity to think well... My sense of creativity and being able to see what is going on and identify 'here is an effective strategy, here is a principle we need to cling to, here are relationships that are important that we need to preserve' [were compromised] ... It was like I had no sense about how to navigate that any more. My thinking was very muddy and I felt immobilized in terms of being able to produce any sort of work or take any sort of action.

Reflecting Rettig's (2006) concerns about the most devastating impact of activist burnout, these effects on individual activists grew into negative effects on their organizations and movements when the activists began withdrawing from their activism. Every participant mentioned, at the very least, reaching a sort of moment of truth in their activism when they needed to decide whether to reject the culture of selflessness and seek self-care (in every case, outside of their SJHR organizations or movements) or continue as they had been working and risk full-scale burnout and, eventually, total withdrawal from their activism.

Several participants described in detail their need to withdraw temporarily from activist work. Shari commented: 'When I left the [SJHR] organization I was at a point [of feeling like] "I don't want to do trafficking work". Years before I was so passionate about it. That was all I wanted to do, all I wanted to think about or read about or talk about.' Others described 'cut[ting] back on public activism', needing 'to take a break', and feeling 'like I just need to quit [my activism]'.

\section{Discussion}

The results of this study lend support to some of the existing scholarship on activist burnout in general and SJHR activist burnout in particular, but complicate and provide new insights into the experiences of SJHR activists in the United States as well. In terms of the symptoms of activist burnout, the three major symptoms identified here-(1) the deterioration of physical health; (2) 
the deterioration of psychological and emotional health; and (3) hopelessness-were similar in nature to both Schaufeli and Buunk's (2002) and Maslach and Gomes's (2006) symptom typologies, both of which included physical, affective, and dispositional components. This study uncovered how participants tracked these components to very specific conditions: clinical depression, cancer, and chronic insomnia.

Based on how participants characterized the symptoms of their burnout a choice of stronger language-not just affective manifestations (Schaufeli and Buunk 2002), but the deterioration of psychological and emotional healthwould better describe the urgency of what the activists reported experiencing. The participants experienced exhaustion (Maslach and Gomes 2006), and associated it with specific conditions that affected their health and drove all of them at some point to desert their activism, at least temporarily. Certainly people engaged in all kinds of work can experience these conditions. Equally certain is that all of the participants have experienced health concerns in their lives that they did not associate directly with activist burnout. It is impossible, or at least beyond the scope of this study, to know for certain what combination of factors might have made participants more or less susceptible to the conditions they described. Regardless, that participants perceived connections between their activism and very specific conditions is, itself, notable, as the intent in this study was to understand how SJHR activists characterize the symptoms, causes, and implications of activist burnout.

In terms of the causes of activist burnout, most notably, participants' experiences with the lack of attention to burnout in SJHR activist organizations and movements and with how the culture of selflessness contributed to their burnout were consistent with the conditions Rodgers (2010) identified among human rights activists in Amnesty International and Plyler (2006) found among social justice activists in Toronto. Adding new insights to their scholarship, this study showed that feelings of guilt and shame associated with considering one's own well-being, which many participants described as being socialized into them in their activist communities, play a considerable role in this culture. The culture of selflessness was so consistently apparent across participants' experiences in various movements that with only two exceptions the activists, some with more than three decades of activism experience, could not think of a single conversation or bit of mentoring about self-care they had experienced within their SJHR organizations and movements or among their communities of activists. Many described cultures that were hostile even to mere conversations about stress and individual well-being. Eventually they decided as a means of survival that they would go outside of those organizations and movements to find support. These findings suggest an even more dire situation than what is captured by Rodgers's (2010) culture of selflessness conception. Patrice, an interviewee, referred instead to a 'culture of martyrdom'-a term that better captures the experiences shared by the activists interviewed for this study. 
Many participants both described the deleterious effects of this culture and discussed instances of their complicity with the culture. It is an oversimplification, then, to suggest that the culture of martyrdom is imposed upon activists who are passive victims. Activists, after all, are running SJHR movements and many SJHR organizations. Understanding the culture of selflessness or of martyrdom in a more complex way requires a recognition of the role that the participants' deep sensitivities regarding their work, and the resulting emotional labour (Goodwin and Pfaff 2001) they invest in that work, may play in their participation sustaining the conditions that often result in burnout. Further study should dig more deeply into this complexity. In other words, activist burnout is not as simple as something that happens to activists who once were emotionally and physically healthy and then, upon involving themselves with SJHR activist communities, became unhealthy. The culture of martyrdom and activist burnout more generally should be understood in a context that considers the emotional connection SJHR activists tend to have to their activism (Maslach and Gomes 2006) - the connection that underlies the emotional labour they invest in that activism. As Kovan and Dirkx (2003: 112) explained: 'Caring deeply about one's work sometimes brings with it the risks of feeling overwhelmed, discouraged, and depressed'. Digging more deeply into this phenomenon, Rodgers (2010) hypothesized that some activists, accustomed to the charged nature of social justice and human rights issues, might seek out work environments that are emotionally charged.

This could help explain the interpersonal challenges experienced by many of the interviewees in their organizations and movements. In addition to the culture of selflessness or martyrdom, participants described troubled withinmovement relationships and their difficulty dealing with the slowness of change as primary causes for their activist burnout. It may seem counterintuitive to imagine such deleterious levels of interpersonal discord within social justice and human rights organizations and movements, particularly those related to human justice issues like racism and sexism. However, scholars have suggested that the interpersonal discord could be related to the same sorts of internal and internalized issues that make SJHR activists particularly susceptible to burnout to begin with. Nair (2004: 30), in her narrative about experiencing and then recovering from SJHR activist burnout, explained: 'often the activist terrain becomes the playground to enact, externalise, and act out inner polarities and unprocessed tensions', which is common among people who are so deeply committed to what they perceive as such critical work.

In order to prepare to respond more effectively to these challenges it is important to distinguish between burnout causes that can be remedied programmatically or institutionally, such as the lack of conversation about self-care in activist organizations, and those that cannot be eliminated easily or at all, such as participants' deep sensitivities to SJHR concerns. It might seem sensible to focus initially on resolving the former, which also include the infighting 
and tense relationships identified by the participants, by identifying patterns of organizational culture that are damaging to activists and by developing networks of people who can work with organizations and movements to improve these conditions. The latter cannot be resolved programmatically or with careful facilitation. However, their impacts can be mitigated by equipping individual activists with strategies for managing their emotional investments.

We have been deeply involved with SJHR movements and organizations in the United States. We have attended SJHR events such as racial justice, children's rights, and animal rights activist gatherings, in which conversations about burnout and activist sustainability occurred, but always at the margins, often as part of optional early-morning meditations or evening dialogue circles, and almost always focused on coping strategies rather than on remedying troubling cultural conditions within SJHR movements. We, too, have seen first-hand evidence of an unwillingness on the parts of SJHR leaders and organizers in the United States to make the issue of burnout a central concern in their movements, despite the fact that it can be such a disruptive force in those movements. As Plyler (2006: 123) put it:

Instead of figuring out ways to take care of ourselves and each other, social justice groups lose brilliant and committed activists to burnout, disillusionment and poor health. As a result, movements are plagued by fragmentation, lack of reflection and discussion, and 'wheel reinventing' that keeps them from moving their agendas forward.

The lack of attention to activist burnout within SJHR discourses and practices has deleterious effects for the societies in which activists are doing their work and the marginalized communities in those societies. As the evidence for this continues to mount, activists and activist organizations should begin to develop intervention tools and to introduce paths towards organizational adjustment and self-care, not just to sustain individual activists, but also to sustain SJHR movements. By distinguishing individual-dispositional causes of burnout from organizational-structural causes, we prepare ourselves to respond to all of them more effectively and to make sure that we are, indeed, responding to all of them.

Unfortunately, scholars have produced little research examining the impact of specific types of interventions that could mitigate burnout by bolstering activists' well-being. The small amount of research that does exist, however, hints at some compelling possibilities. At the individual-dispositional level Jacob et al. (2009) pointed to the potential for meditative and other mindful experiences for advancing activists' subjective well-being. Hart (2013) described a ten-week intervention for women activists using ecological drama therapy to explore the theme of self-care. More scholarship is needed to examine the impacts of these interventions on the long-term sustainability of SJHR activists and SJHR movements. We intend to turn next, for example, to 
building on the work of Jacob et al. (2009) and Hart (2013) by examining the impacts of mindfulness practices on the burnout experiences of SJHR activists.

Even less is known about SJHR organizations' attempts to address burnout at the organizational-structural level. Nepstad (2004) tracked activist sustainability strategies engaged within the Plowshares movement in the United States, an organization she presented as a sort of model for facilitating activist sustainability. However, her analysis of the organization's initiatives predominantly uncovered vaguely described programmes designed to strengthen individual coping strategies, such as by providing networks for emotional support. Regarding organizational culture, the Plowshares organization engaged workers in community-building exercises, which might have contributed to a healthier work environment with less infighting and higher levels of comfort discussing challenges like burnout, although Nepstad (2004) did not discuss the specific outcomes of these exercises.

Based on our analysis and buttressed by our own experiences in SJHR organizations and movements, we encourage SJHR activists, and particularly movement leaders, to examine ways in which the cultural dynamics of activist organizations and movements might foster a culture of martyrdom that dissuades conversations about burnout or that unintentionally breeds infighting and tension. Certainly individual activists always will carry their passions into disagreements about philosophical and practical approaches for resolving injustice; we find it impossible to imagine a tension-free SJHR movement in that regard. But to the extent that the tensions and infighting identified by the activists in this study are related to a larger culture in which individual activists might be suffering the symptoms of burnout or other maladies related to the stressors of SJHR work in seclusion, it is reasonable to believe that the high rates of burnout reported by Rodgers (2010), Klandermans (2003), and others will continue to be a threat to the effectiveness of SJHR movements.

As activists who have been involved in a wide variety of SJHR movements and organizations, we are intimately familiar with, in Patrice's words, the 'culture of martyrdom'. Given its apparent preponderance, might it serve any positive purposes within SJHR movements? It could be easy to assume, for instance, that such a culture would help breed a sense of urgency among workers or help project a sense of commitment to possible funders and supporters. The scholars behind the somewhat slim existing scholarship that addresses this point - a combination of studies of specific SJHR movements and organizations (e.g. Plyler 2006; Rodgers 2010) and individual accounts from within these movements and organizations (e.g. Nair 2004; Pigni 2013) - appear to agree, at least implicitly, that this culture is entirely deleterious. The participants in this study roundly agree; not a single one identified any positive aspect of this particular aspect of the cultures of their organizations or movements. A broader understanding of the scholarship on activist burnout helps explain this. For example, as detailed earlier, a majority of 
people who become involved in SJHR activist causes-particularly when they, like our participants, are doing so outside of their paid employment-come into their activist work with a sense of urgency and a deep emotional connection to the movements in which they engage (Goodwin and Pfaff 2001; Kovan and Dirkx 2003). In other words, the sense of urgency does not need to be manufactured through cultural conditions within organizations or movements. It is illogical to assume that such a deep connection and sense of urgency can be sustained, anyway, within movement or organizational cultures that eat away at activists' emotional health, physical health, and spirits.

Similarly, one might wonder how it would look or what it would mean if SJHR movements and organizations did begin to allocate resources such as time, money, and perhaps even staff to help quell the tide of burnout. Is there a cost, beyond this allocation of resources, to doing so? Several participants spoke to this dilemma as they described their initial hesitance to tend to their own well-being or to seek help for their burnout. Reflecting the culture of martyrdom, they saw self-care as a 'luxury' or 'self-indulgent'. Further reflecting that culture, some worried that the people or non-human animals for whom they were advocating did not have those luxuries, so they, as activists, should not have them either. Notably, though, consistent with discussions of these phenomena in existing scholarship (Kovan and Dirkx 2003; Rettig 2006), every participant who characterized their views in this way eventually came to see those views as deleterious, not only to themselves as individual activists, but also to the movements in which they were engaged. In the end, attention to burnout and self-care among activists helps to keep individual activists engaged in their activism and, as a result, makes SJHR movements and organizations more consistent and efficient in the long run. As Rettig (2006: 16) explained, the cost of burnout, even in the case of a single activist, is that by burning out 'she deprives her organization and movement of her valuable experience and wisdom'. She also 'deprives younger activists of a mentor, thus making them more likely to burn out'.

Concerns might be raised about how attention to activist self-care might look to victims who do not have the option to take a break from the repression they are facing. It is important to remember, first of all, that many SJHR activists-several of the participants in this study, including the participants of colour engaged in racial justice activism-are themselves the targets of the injustice they are fighting through their activism. We suspect that initially some organizations or movements would face criticism if they began to allocate resources toward activist well-being because by doing so they would be challenging a strongly-embedded expectation of selflessness. We also suspect, however, that organizations and movements that actively address these challenges will become more efficient in their activism because they will experience less turnover and sustain stronger commitments among activists. Although these are speculations, there is nothing in the existing scholarship or the data analysed for this study that suggests that, given time to adjust to new norms, 
tending more mindfully to the sustainability of activists would have anything other than a positive, sustaining effect on SJHR movements.

A most urgent point of departure for doing so is addressing the racism that several of this study's participants of colour described as existing within SJHR circles. Although it might seem counter-intuitive that issues of bias and prejudice would find their way into SJHR movements, some of which were instigated to eliminate bias and prejudice and their structural implications, scholars have pointed to the troubling impacts of racism within a variety of SJHR movements in the United States, such as the prison reform (Appel 2003), feminist (Lorde 1988), and queer (Vaccaro and Mena 2011) movements. Whereas the activists interviewed for this study did not refer specifically to parallel issues such as sexism or economic injustice within their movements, other studies have uncovered these conditions and their negative impacts on SJHR movements and organizations (e.g. Scott 2000; Ward 2004). This is an important reminder that SJHR movements and organizations are not uniquely equitable and just. In the short term, issues like these threaten to hasten burnout among entire identity groups within movements and movement organizations; in the long run they threaten to result in large numbers of people within those identity groups disassociating from particular movements.

\section{Limitations}

Three important limitations of this study should be noted. First, the sample consisted wholly of activists based in the United States. Although many of those activists are engaged in international activism, working either fully or partially on SJHR issues outside the United States, it is important to acknowledge that challenges facing activists in other parts of the world are informed by their particular regional contexts and should not be assumed to be consistent with this study's findings. For example, although many activists in the United States have experienced the threat or the reality of incarceration, violence, and even death due to their activism, these sorts of threats and realities are escalated, sometimes drastically, in more conflict-ridden or authoritarian regional contexts. Secondly, given the sample size of 22 participants, the findings of this study cannot be extrapolated to all activists, even within the United States. The specifics of the same should be noted, as well. Participants who had experienced and sought strategies to manage burnout, rather than those who had experienced but sought no help for burnout, were sought out for this study because, in the researchers' view, it was likely that the former, by having purposefully confronted it, would have a more sophisticated understanding of the symptoms, causes, and implications of their burnout. In addition, as with any study of this kind, there always is a risk of selection bias, wherein participants who are more likely to have had more extreme experiences may be more likely to desire to share those experiences, and thus be more likely to respond to a request for participants. As a result, the findings of 
this study should not be seen as a broad representation of the experiences of all United States SJHR activists, but rather as one step toward understanding the experiences of a sample of activists who, due to the challenges presented by burnout, were mindful about finding a way, in one participant's words, to 'stay in the game'.

\section{Conclusion}

Despite mounting evidence from this and other studies of the deleterious impact activist burnout is having on individual SJHR activists and, as a result, SJHR movements, a culture of martyrdom that discourages conversations about burnout and self-care persists among those activists and movements. Based on an analysis of interviews with 22 such activists based in the United States, our findings both confirmed and added important new wrinkles to the present understandings of SJHR activist burnout. Participants grappled with the deterioration of their physical and emotional health and with hopelessness, seeing these as symptoms of their burnout. They associated these symptoms with the lack of attention to burnout and self-care in their activist communities, their deep sensitivities to the injustices they were battling in their activism, and infighting and tense relationships among SJHR activists. They recognized that their burnout had significant implications, both for their effectiveness as activists and for their abilities to remain involved in their activism. Together, these findings indicate the desperate need for greater attention to burnout and self-care across SJHR movements and activist organizations, not just for the sustainability of activists, but for the sustainability and success of movements for a more equitable and just world.

\section{Funding}

This work was supported by Center for the Advancement of Well-Being, George Mason University.

\section{References}

Appel, L. 2003. White Supremacy in the Movement against the Prison-Industrial Complex. Social Justice 30(2): 81-8.

Couch, J. 2004. This is What Democracy Looks Like: The Genesis, Culture and Possibilities of Anti-Corporate Activism. Unpublished $\mathrm{PhD}$ thesis. Victoria University, Melbourne.

Cox, L. 2009. 'Hearts With One Purpose Alone'? Thinking Personal Sustainability in Social Movements. Emotion, Space and Society 2: 52-61. Available at http://eprints. nuim.ie/1538/1/LCHearts_with_one_purpose_alone_LBedited.pdf (last referenced 16 September 2015).

2011. How Do We Keep Going? Activist Burnout and Personal Sustainability in Social Movements. Available at http://eprints.nuim.ie/2815/1/LC_How_do_ we_keep_going.pdf (last referenced 16 September 2015). 
Creswell, J. W. 2009. Research Design: Qualitative, Quantitative, and Mixed Methods Approaches (3rd ed). Los Angeles, CA: Sage Publications.

Downton, J., and P. Wehr. 1998. Persistent Pacifism: How Activist Commitment is Developed and Sustained. Journal of Peace Research 35(5): 531-50.

Freudenberger, H. J. 1974. Staff Burnout. Journal of Social Issues 30: 159-65.

Gomes, M. 1992. The Rewards and Stresses of Social Change: A Qualitative Study of Peace Activists. Journal of Humanistic Psychology 32(4): 138-46.

Gomes, M. E., and C. Maslach. 1991. Commitment and Burnout among Political Activists: An In-Depth Study. Paper presented at the International Society of Political Psychology, Helsinki.

Goodwin, J., and S. Pfaff. 2001. Emotion Work in High-Risk Social Movements: Managing Fear in the US and East German Civil Rights Movements. In J. Goodwin, J. Jasper and F. Polletta (eds), Passionate Politics: Emotions and Social Movements: 282-302. University of Chicago Press.

Hart, R. 2013. Widening Circles of Care: Exploring Self-Care with Activists Using Ecological Drama Therapy. MA Thesis. Available at http://spectrum.library. concordia.ca/977967 (last referenced 16 September 2015).

Hopgood, S. 2006. Keepers of the Flame: Understanding Amnesty International. Ithaca, NY: Cornell University Press.

Jacob, J., E. Jovic, and M. B. Brinkerhoff. 2009. Personal and Planetary Well-Being: Mindfulness Meditation, Pro-Environmental Behavior and Personal Quality of Life in a Survey from the Social Justice and Ecological Sustainability Movement. Social Indicators Research 93(2): 275-94.

Klandermans, B. 2003. Disengaging from Movements. In J. Goodwin and J. M. Jasper (eds), The Social Movements Reader: Cases and Concepts: 116-27. Malden, MA: Blackwell.

Kovan, J. T., and J. M. Dirkx 2003. 'Being Called Awake': The Role of Transformative Learning in the Lives of Environmental Activists. Adult Education Quarterly 53(2): 99-118.

Lorde, A. 1988. A Burst of Light. Ithaca, NY: Firebrand Books.

Maslach, C., and M. E. Gomes. 2006. Overcoming Burnout. In R. M. MacNair (ed.), Working for Peace: A Handbook of Practical Psychology and Other Tools (2nd ed.): 43-9. San Luis Obispo, CA: Impact Publishers.

Maslach, C., and M. P. Leiter. 2005. Reversing Burnout: How to Rekindle Your Passion for Your Work. Stanford Social Innovation Review 3(4): 42-9.

Nair, N. 2004. On 'Being' and 'Becoming': The Many Faces of an Activist. Agenda 60: $28-32$.

Nepstad, S. E. 2004. Persistent Resistance: Commitment and Community in the Plowshares Movement. Social Problems 51(1): 43-60.

Patton, M. Q. 1990. Qualitative Evaluation and Research Methods. Newbury Park, CA: Sage.

Pigni, A. 2013. Practising Mindfulness at the Checkpoint. OpenDemocracy. 17 July.

Pines, A. M. 1994. Burnout in Political Activism: An Existential Perspective. Journal of Health and Human Resources Administration 16(4): 381-94. 
Plyler, J. 2006. How to Keep On Keeping On. Upping the Anti 3: 123-34.

Rettig, H. 2006. The Lifelong Activist: How to Change the World Without Losing Your Way. New York: Lantern Books. Online at http://lifelongactivist.com (last referenced 16 September 2015).

Rodgers, K. 2010. 'Anger is Why We're All Here': Mobilizing and Managing Emotions in a Professional Activist Organization. Social Movement Studies 9(3): 273-91.

Schaufeli, W. B., and P. Buunk. 2002. Burnout: An Overview of 25 Years of Research and Theorizing. In M. J. Schabracq, J. A. M. Winnubst and C. L. Cooper (eds), The Handbook of Work and Health Psychology: 383-425. Chichester: Wiley.

Schaufeli, W. B., M. P. Leiter, C. Maslach, and S. E. Jackson. 1996. The Maslach Burnout Inventory: General Survey. In C. Maslach, S. E. Jackson and M. P. Leiter (eds), Maslach Burnout Inventory: 19-32. Palo Alto, CA: Consulting Psychologists Press.

Scott, E. K. 2000. Everyone Against Racism: Agency and the Production of Meaning in the Anti-Racism Practices of Two Feminist Organizations. Theory and Society 29(6): $785-818$.

Strauss, A., and J. Corbin. 1990. Basics of Qualitative Research: Grounded Theory Procedures and Techniques. Newbury Park, CA: Sage.

Vaccaro, A., and J. Mena. 2011. It's Not Burnout, It's More: Queer College Activists of Color and Mental Health. Journal of Gay and Lesbian Mental Health 15(4): 339-67.

Ward, J. 2004. Not All Differences are Created Equal: Multiple Jeopardy in a Gendered Organization. Gender and Society 18(1): 82-102.

Wollman, N., and M. Wexler. 1992. A Workshop for Activists: Giving Psychology Away to Peace and Justice Workers. Journal of Humanistic Psychology 32(4): 147-56.

\section{Appendix 1. Interview protocol}

(1) How would you characterize the human rights or social justice activism that you do? Are there particular human rights or social justice issues on which you focus most intently?

(2) How did you initially get involved in doing human rights or social justice work? What drew you to the work that you do?

(3) To what extent have you experienced activist burnout related to your human rights or social justice work?

(4) How has it affected you, specifically?

(5) To what extent do you see burnout among the people with whom you do the human rights or social justice work you do?

(6) Have you ever had mentoring or training on how to cope with the emotional, physical, and psychological toll that doing human rights or social justice work can take on activists and advocates? If so, what was the nature of the mentoring or training? Has it been effective? 
(7) How do you tend to your own well-being as it relates to your human rights and social justice activism and advocacy?

(8) Is there a time you can remember when you were especially burned out, struggling to persevere in your activist activities? How did you care for yourself? How did you make it through that time?

(9) In what specific well-being, mindfulness, or self-care practices have you engaged in order to sustain your energy as an activist or advocate? How did you come to identify and adopt these practices?

(10) In some circles of human rights and social justice activists, self-care or engaging in well-being or mindfulness practices has been seen as a luxury or even a marker of privilege rather than an important strategy for sustaining social change work. Why, in your opinion, do some human rights and social just workers have that perception? Did you ever have that perception? If so, how did you overcome it, if at all?

(11) Have your well-being, mindfulness, and self-care practices helped you to be a more effective activist or advocate? If so, how?

(12) To what extent do you see your well-being, mindfulness, and self-care practices as interrelated with your human rights and social justice work? 